\title{
Gene Structure and Glial Expression of the Glycine Transporter GlyT1 in Embryonic and Adult Rodents
}

\author{
Ralf H. Adams, ${ }^{1}$ Kohji Sato, ${ }^{1,2}$ Shoichi Shimada, ${ }^{3}$ Masaya Tohyama, ${ }^{3}$ Andreas W. Püschel, ${ }^{1}$ and Heinrich \\ Betz' \\ ${ }^{1}$ Abteilung Neurochemie, Max-Planck-Institut für Hirnforschung, D-60528 Frankfurt/Main, Germany and ${ }^{2}$ Department \\ of Neuroanatomy, Biomedical Research Center, and ${ }^{3}$ Department of Anatomy and Neuroscience, Osaka University \\ Medical School, Osaka, Japan
}

\begin{abstract}
$\mathrm{Na}^{+} / \mathrm{Cl}^{-}$-dependent glycine transporters are crucial for the termination of neurotransmission at glycinergic synapses. Two different glycine transporter genes, GlyT1 and GlyT2, have been described. Several Isoforms differing in their $5^{\prime}$ ends originate from the GlyT1 gene. We have determined the genomic structure of the murine GlyT1 gene to elucidate the genetic basis underlying the different isoforms. Analysis of cDNA $5^{\prime}$-ends revealed that the GlyT1a and $1 \mathrm{~b} /$ 1c mRNAs are transcribed from two different promoters. During murine embryonic development GlyT1 mRNAs were detectable by RNase protection assays as early as embryonic day E9 and reached maximal levels between E13 and E15. In situ hybridization revealed GlyT1 expression in the developing spinal cord mainly in the ventral part of the ventricular zone at E12. At later stages (E15) transcripts were also found in the lateral half of the basal and intermediate gray matter. In contrast, the second glycine transporter gene GlyT2 displayed a completely different expression pattern. At E11 it is expressed in the mantle zone, and at later stages throughout the ventral horns. In the adult rat brain and spinal cord, GlyT1 hybridization signals were found exclusively in glial cells. Our data indicate that GlyT1 is an early marker of neural development and encodes gliaspecific transporter proteins.

[Key words: glycine transporter, gene structure, alternate promoters, glycine receptor, in situ hybridization, embryonic development, spinal cord]
\end{abstract}

Iremendous progress has been made in understanding the molecular mechanisms of synaptic transmission, and an increasing number of both pre- and postsynaptic proteins has been studied at the molecular level. With the recent cloning of several members of the $\mathrm{Na}^{+} / \mathrm{Cl}^{-}$-dependent neurotransmitter transporter family another important synaptic component, neurotransmitter uptake, has become amenable to functional studies. Neurotransmitter transporters are located both in the presynaptic membrane

\footnotetext{
Received July 13, 1994; revised Sept. 23, 1994; accepted Sept. 27, 1994.

We thank Birgit Pilz for expert technical assistence and M. Ehms-Sommer for help with photography. Part of this work was supported by the Deutsche Forschungsgemeinschaft (Leibniz-Programm and SFB 269), by the Ministry of Education, Science and Culture of Japan, and by a postdoctoral fellowship of the Alexander von Humboldt Foundation to K.S.

Correspondence should be addressed to $\mathrm{H}$. Betz, Abteilung Neurochemie, Max-Planck-Institut für Hirnforschung, Deutschordenstrasse 46, D-60528 Frankfurt/Main, Germany.

Copyright (C) 1995 Society for Neuroscience $0270-6474 / 95 / 152524-09 \$ 05.00 / 0$
}

and on surrounding glial cells (for a recent review, see Schloss et al., 1994) and are crucial for the rapid removal of neurotransmitters from the synaptic cleft. This reuptake terminates synaptic transmission and helps to replenish transmitter pools in the presynaptic nerve terminal.

Cloning of the transporters for GABA (Guastella et al., 1990) and norepinephrine (Pacholczyck et al., 1991) allowed the subsequent isolation of a number of cDNAs encoding homologous $\mathrm{Na}^{+} / \mathrm{Cl}^{-}$-dependent transporters, including those for dopamine (Giros et al., 1991; Kilty et al., 1991; Shimada et al., 1991; Usdin et al., 1991), 5-HT (Blakely et al., 1991; Hoffman et al., 1991), and glycine (Guastella et al., 1992; Liu et al., 1992b; Smith et al., 1992). All these transporters share a postulated structure of 12 transmembrane domains deduced from hydropathy plots (Guastella et al., 1992; Smith et al., 1992). Several neurotransmitter uptake systems display an unexpected molecular heterogeneity as shown by the cloning of four different GABA (López-Corcuera et al., 1992; Liu et al., 1993a) and glycine (Borowsky et al., 1993; Liu et al, 1993b; Kim et al., 1994) transporter cDNAs. Three of the latter (GlyT1a, 1b, and 1c) are encoded by a single gene and differ only in their amino-terminal region (Kim et al., 1994). The fourth transporter GlyT2 is generated from a separate gene with $48 \%$ amino acid sequence identity to GlyT1 and is pharmacological distinguishable from the different GlyT1 isoforms (Liu et al., 1993b).

The expression of GlyTla and GlyT1b in adult rats and mice has been studied by in situ hybridization (Guastella et al., 1992; Liu et al., 1992b; Smith et al., 1992; Borowsky et al., 1993). Both variants are expressed in many regions of the CNS including hypothalamus, mesencephalon, brainstem, and spinal cord. GlyT1a mRNA is present in regions with a high density of neuronal cell bodies and was proposed to colocalize with inhibitory glycine receptor subunit mRNA (Borowsky et al., 1993). In addition GlyTla is expressed in several peripheral tissues, for example, liver, lung, and stomach. In contrast, in brain the GlyTlb mRNA was suggested to colocalize with the NMDA subtype of glutamate receptors (Smith et al., 1992). Glycine transporters might modulate the concentration of glycine at its coagonist binding site on the NMDA receptor (Johnson et al., 1987; Kuryaluw et al., 1994) by uptake into neighboring glial cells or by reverse transporter-mediated release (Attwell et al., 1992, 1993), and thereby affect the efficacy of glutaminergic synapses. The GlyT2 mRNA was found to be restricted to the central nervous system and to be mainly localized in spinal cord and brainstem (Liu et al., 1993b), which correlates well with the distribution 
Table 1. Origin of GlyT1-specific probes used in this article

\begin{tabular}{|c|c|c|}
\hline & Probe & Reference \\
\hline Genomic screening & $\begin{array}{l}460 \mathrm{bp} \text { PCR-fragment derived from genomic DNA } \\
\text { with primers from exon } 3 \text { (sense) and } 4 \\
\text { (antisense), includes } 0.4 \mathrm{~kb} \text { intronic sequence }\end{array}$ & Present results \\
\hline cDNA screening & $\begin{array}{l}\text { GlyT740: PCR-fragment including nucleotides } \\
409-1148 \text { of the rat GlyT } 1 \text { cDNA }\end{array}$ & Guastella et al., 1992 \\
\hline RNase protection assay & $\begin{array}{l}\text { antisense RNA derived from a } 450 \text { bp BglII-BsaAI } \\
\text { fragment corresponding to nucleotides } 210-660 \\
\text { of the mouse GlyTla cDNA }\end{array}$ & Liu et al., 1992b \\
\hline Northern blot & $\begin{array}{l}0.9 \mathrm{~kb} \text { BglII fragment of the Glytla cDNA } \\
\text { nucleotides } 210-1121\end{array}$ & Liu et al., 1992b \\
\hline \multirow{3}{*}{$\begin{array}{l}\text { In situ hybridization of } \\
\text { mouse embryo } \\
\text { sections }\end{array}$} & $\begin{array}{l}\text { GlyTla/b: } 1.9 \mathrm{~kb} \text { Ncol-BsaBI fragment of the } \\
\text { mouse GlyT1 a cDNA, nucleotides 239-2092 }\end{array}$ & Liu et al., 1992b \\
\hline & $\begin{array}{l}\text { GlyTla: } 209 \text { bp EcoRI-BglII fragment of the } \\
\text { mouse GlyT1a cDNA, nucleotides } 1-210\end{array}$ & Liu et al., 1992b \\
\hline & $\begin{array}{l}\text { GlyT1b: } 253 \text { bp PCR fragment derived from } \\
\text { mouse genomic DNA including coding sequence } \\
\text { of exon } 1 \mathrm{~b} \text { and } 208 \text { bp upstream from the start } \\
\text { codon }\end{array}$ & $\begin{array}{l}\text { Present results: } \\
\text { Fig. } 2\end{array}$ \\
\hline $\begin{array}{l}\text { In situ hybridization of } \\
\text { rat brain sections }\end{array}$ & $\begin{array}{l}\text { Antisense oligonucleotides complementary to bases } \\
536-580 \text { or } 1813-1857 \text { of the rat GlyTlb cDNA }\end{array}$ & Smith et al., 1992 \\
\hline
\end{tabular}

of inhibitory, strychnine-sensitive glycine receptors (Betz, 1992).

To further understand the roles of the different GlyT1 isoforms in glycinergic and glutaminergic neurotransmission we analyzed both the genomic structure and the developmental and regional expression of the murine GlyT1 gene. Our data show that two isoforms, GlyT1a and $1 \mathrm{~b}$, originate from transcription initiated at alternate promoters, whereas GlyT1c is a splice variant of the $1 \mathrm{~b}$ transcript. In situ hybridization revealed that in the CNS GlyT1 transcripts are expressed in glial cells.

\section{Materials and Methods}

Isolation of the GLYT1 cDNA. We screened $1.6 \times 10^{6} \mathrm{pfu}$ of a mouse brain cDNA library (Stratagene, Ileidelberg, Germany) with a $740 \mathrm{bp}$ PCR fragment (Glyt740 probe; see Table 1), and a single hybridizationpositive clone was isolated. Partial sequencing showed that the cDNA sequence was identical to that published by Liu et al. (1992b).

Full-length cDNA 5 '-ends were isolated by using the 5'-RACE Ready cDNA kit (Clontech, Palo Alto, CA). Two subsequent PCR amplifications were performed with the supplied anchor primer (sense) and different combinations of nested gene-specific primers (antisense) $5^{\prime}$ CCATCATACCATAGCCCACG-3' (exon 4), 5'-GAAGATCAGCATGATGAAGTA-3' (exon 3), 5'-GTGTGAGGTTCTGGTCCTTC-3' (primer G, exon 2), $5^{\prime}$-CTGTTCTGGGGAAGGGGTGGC-3' (primer F, exon $1 \mathrm{~b}$ ) according to the manufacturer's specifications. The fragments obtained were subcloned into Bluescript (Stratagene, Heidelberg, Germany) and sequenced.

Isolation and analysis of genomic clones. The GlyT1 cDNA was labeled with digoxigenin-11-dUTP (DIG DNA labeling and detection kit, Boehringer Mannheim, Mannheim, Germany) and used for screening a mouse genomic library constructed in the vector $\lambda F I X$ (Stratagene, Heidelberg, Germany) following standard protocols (Sambrook et al., 1989). In addition three overlapping genomic P1 clones (P1 \#605, \#606, \#607) in the vector pAD10sacBII were obtained by a PCR screen performed by Genome Systems (St. Louis, MO; primers used: sense $5^{\prime}$ CTTCGGCCAGTTTGCAAGCC-3', antisense 5'-CCATCATACCATAGCCCACG-3'; see Table 1). A genomic map comprising $18 \mathrm{~kb}$ of the GlyT1 gene was generated by sequencing of selected genomic subclones, PCR and restriction mapping of clone AGMGT1 (Cosmid mapping kit, Takara, Kyoto, Japan). Genomic DNA fragments were se- quenced after subcloning into Bluescript using a T7 DNA sequencing kit (Pharmacia, Freiburg, Germany) and synthetic oligonucleotide primers. Computer analysis was done using the HUSAR 3.0 software (Deutsches Krebsforschungszentrum, Heidelberg, Germany).

Polymerase chain reaction and recombinant DNA. Probes for cDNA screening and in situ hybridization were generated by amplifying DNA fragments from rat brain cDNA (GLYT1: Glyt740 probe, sense 5'GGTATGATGGTGGTGTCCACGTAC-3', antisense 5'-GACACATCCACACCCAGGTGATTG- $\left.3^{\prime}\right)$ by 30 cycles of denaturation $(45 \mathrm{sec}$, $94^{\circ} \mathrm{C}$ ), annealing $\left(45 \mathrm{sec}, 65^{\circ} \mathrm{C}\right)$ and extension $\left(1 \mathrm{~min}, 72^{\circ} \mathrm{C}\right), 50 \mathrm{ng}$ of mouse genomic DNA (300 bp GlyR $\alpha$ 1: sense 5'-GGAGAATTCTTCAGGATGATGAGGGTGG-3', antisense 5'-GGGGATCCAGCCTTCACTTGTTGTGGAC-3'; 300 bp GlyR $\alpha 2$ : sense: 5'-CCCTTTGCATGGTGATGGCG-3', antisense: 5'-GTTCACTAGCTGCCGGTACA3'; 340 bp GlyR $\beta$ : sense 5'-GCGGATCCCATAATTGCTGATCTGTG3', antisense: 5'-GGGATTCGATACTGCATACATGGAC-3') by $30 \mathrm{cy-}$ cles of denaturation $\left(1 \mathrm{~min}, 94^{\circ} \mathrm{C}\right)$, annealing $\left(1.5 \mathrm{~min}, 60^{\circ} \mathrm{C}\right)$ and extension $\left(1.5 \mathrm{~min}, 72^{\circ} \mathrm{C}\right.$ ), or mouse brain cDNA ( $300 \mathrm{bp}$ GlyT2: sense 5'-GGGGATCCCACAGGGTGGAATCTACATG-3', antisense ${ }^{\prime}$ 'GGGAATTCGCATCAGCCATCCAAGCACC- $3^{\prime}$ ) by 30 cycles of denaturation $\left(1 \mathrm{~min}, 94^{\circ} \mathrm{C}\right)$, annealing $\left(1.5 \mathrm{~min}, 55^{\circ} \mathrm{C}\right)$ and extension $(1.5$ $\min , 72^{\circ} \mathrm{C}$ ).

PCR analysis of GlyT1 cDNA 5 '-ends was done with primers A 5 'GGCCAGGGGAGCCGCTCAGG-3' (sense), B 5'-AGCCTTCGTCACTCTCCAAAC-3' (sense), C 5'-TTTCCTACCATGGTGGCAGT-3' (antisense), D 5'-CCCTCGCTGGGCTGCATCAG-3' (sense), E 5'-GAGATGAGGTGAAGTAATTG-3' (sense), F 5'-CTGTTCTGGGGAAGGGGTGGC-3' (antisense), and G 5'-GTGTGAGGTTCTGGTCCTTC- $3^{\prime}$ (antisense) by 30 cycles of denaturation $\left(1 \mathrm{~min}, 94^{\circ} \mathrm{C}\right.$ ), annealing $\left(1 \mathrm{~min}, 58^{\circ} \mathrm{C}\right)$ and extension $\left(2 \mathrm{~min}, 72^{\circ} \mathrm{C}\right)$. The following products were obtained: primers A and C, $420 \mathrm{bp}$; B and C, $360 \mathrm{bp}$; A and G, 510 $\mathrm{bp}$; and $\mathrm{E}$ and F, $230 \mathrm{bp}$. The fragments were cloned into Bluescript, and the identity of the clones was verificd by didcoxy scquencing.

PolyA $^{+}$RNA was purified using the polyATract system (Promega, Heidelberg, Germany). cDNA was prepared from $1 \mu \mathrm{g}$ of adult rat or mouse brain polyA ${ }^{+}$RNA using a cDNA synthesis kit (Boehringer Mannheim, Mannheim, Germany) in a final volume of $20 \mu \mathrm{l}$ according to the manufacturer's specifications. Aliquots of the cDNA $(1 \mu \mathrm{l})$ were used for PCR reactions.

A $1.9 \mathrm{~kb} \mathrm{NcoI-BsaBI}$ fragment containing most of the GlyTla cDNA was cloned into Bluescript (Stratagene, Heidelberg, Germany) and used for in situ hybridization (probe GlyT1a/b). Probe GlyT1a was generated 
from a $210 \mathrm{bp}$ EcoRI-BglII fragment of the GlyT1a cDNA and probe GlyT1b from a 253 bp PCR fragment generated from genomic DNA corresponding to primers: $5^{\prime}$-CCCTCGCTGGGCTGCATCAG-3' (sense), 5'-CTGTTCTGGGGAAGGGGTGGC-3' (antisense). A 450 bp BglII-BsaAI fragment of the GlyT1 cDNA was used as a template to generate antisense RNA for RNase protection assays. A 258 bp BamHISacII fragment from the mouse $\beta$-tubulin 5 gene (BTub5, generously provided by $\mathrm{R}$. Balling) was used as internal control in RNase protection assays. All GlyT1-specific probes are listed in Table 1.

RNA isolation and analysis. Mouse embryos were obtained from NMRI mice (Zentralinstitut für Versuchstierzucht, Hannover, Germany). Mice were mated overnight, and the day of detection of vaginal plugs was designated embryonic day zero (E0). Total RNA was prepared from embryos or tissues using the guanidine thiocyanate method (Chirgwin et al., 1979). RNase protection assays were performed as described previously (Piuschel at al., 1990); $100 \mu \mathrm{g}$ of total RNA were used for the hybridization with $6 \times 10^{6} \mathrm{cpm}$ of GlyT1a, and $1 \times 10^{6} \mathrm{cpm}$ of BTub5, antisense RNAs, respectively. In situ hybridization of paraffin embedded embryos (10 $\mu \mathrm{m}$ sections) with ${ }^{35} \mathrm{~S}$-labeled RNA probes was done as described (Püschel et al., 1992). RNA probes were generated by in vitro transcription of subcloned cDNA fragments using T3 or T7 RNA polymerase (New England Biolabs, Schwalbach/Taunus, Germany). The antisense RNAs were labeled by the incorporation of $\alpha-{ }^{35} \mathrm{~S}-\mathrm{UTP}$ ( $30 \mathrm{TBq} /$ mmol, Amersham Buchler, Braunschweig, Germany) for in situ hybridization experiments, or of $\alpha{ }^{-3} \mathrm{P}-\mathrm{UTP}(37-110 \mathrm{TBq} / \mathrm{mmol}$, Amersham Buchler, Braunschweig, Germany) for RNase protection assays.

Northern blotting was performed as described recently (Püschel et al., 1994), using a $0.9 \mathrm{~kb}$ BgIII fragment from the Glyt1a cDNA (Liu et al., 1992b; Table 1) labeled with ${ }^{32} \mathrm{P}$ as a probe.

In situ hybridization analysis of GlyT1 expression in adult rat brain was done as described previously (Sato et al., 1993) using ${ }^{35}$ S-labeled antisense oligonucleotides complementary to bases $536-580$ or to 1813-1857 of the rat GlyT1b cDNA (Smith et al., 1992).

\section{Results}

Structure of the murine GlyT1 gene

In order to understand the genetic origin of the various GlyT1 isoforms we determined the structure of the corresponding gene. An initial screen of a mouse genomic $\lambda F I X$ library with the GlyT 1 cDNA yielded only a single clone containing exons $1 \mathrm{~b}-$ 4. To obtain additional sequences a genomic P1-library was screened by PCR, and three overlapping clones were isolated. The structure of the GlyT1 gene was determined by sequencing subclones of the P1-inserts (Fig. 1A) with primers derived from the published mouse GlyT1 cDNA sequence.

The coding sequence of the murine GlyT1 gene is divided into 13 exons distributed over a region of $18 \mathrm{~kb}$ (Fig. $1 \mathrm{~A}$ ), with most of the coding exons being clustered (exons 2-13) within 7 $\mathrm{kb}$. In contrast, the exons encoding the alternative amino-terminal ends of the GlyT1 proteins are separated by larger introns. The size of the introns in the GlyT1 gene and the sequences of the exon-intron junctions are listed in Table 2. The intron-exon structure of the GlyT1 gene is very similar to that of the GABA transporter gene, GAT1 (Liu et al., 1992a). With few exceptions, homologous sequences are encoded by exons of identical size in both genes. The sequences corresponding to exons 4 and 8 of GlyT1 are split into two exons in GAT1. The position of the intron-exon junction separating exons 6 and 7 of GlyT1 differs by 8 bp in the GAT1 gene, suggesting that this site might have evolved independently in both genes after duplication of a common precursor. Finally, the sequences and the genomic organization of the GlyT1 5'-ends (exons 0a, 1a, 1b, 1c) are very different from the corresponding regions of GAT1.

The schematic representation of the putative transmembrane topology of GlyT1 (Fig. 1C) illustrates that most of the transmembrane regions of the protein are encoded by a single exon. This is consistent with the observation that individual exons often correspond to structural units of the encoded protein (Dorit
A

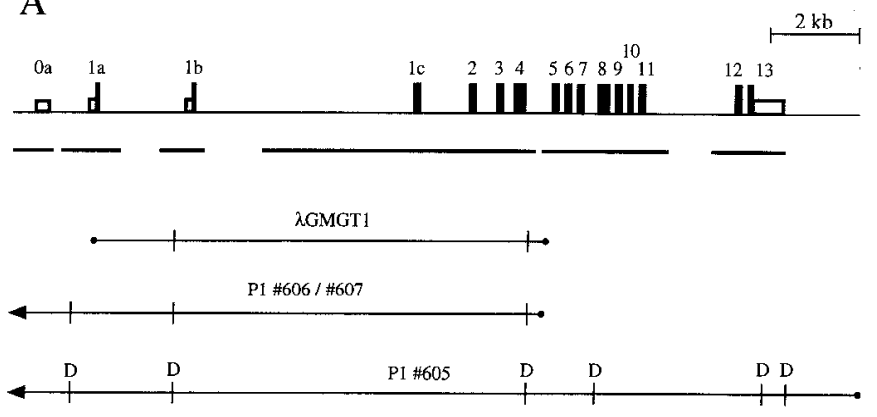

B
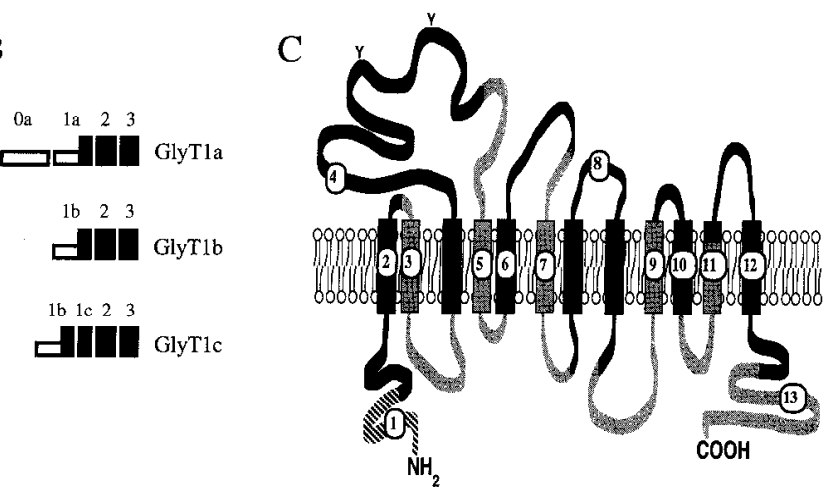

Figure 1. Organization of the mouse GlyT1 gene. A, Schematic representation of the genomic sequence of GlyT1. The intron-exon organization of the sequences corresponding to base pairs 15-3164 of the GlyT1 cDNA (Liu et al., 1992b) is shown. Base pairs 1-14 of the cDNA (Liu et al., 1992b) are identical to the sequence of the Uni-ZAP adaptors (Stratagene). Exons are represented as boxes. Coding regions are shown as black boxes, noncoding sequences as open boxes. Solid bars under the schematic structure indicate sequenced regions of the gene. Numbering of the exons is provisional, because additional exons might exist. The lower panel displays the maps of genomic GlyT1 sequences present in the isolated $\lambda$ and P1 clones. Restriction sites for the enzyme DraI are marked $(D)$. $B$, Representation of $5^{\prime}$-exonic sequences in different GlyT1 mRNAs. $C$, Proposed transmembrane topology of the GlyT1 protein (modified after Schloss et al., 1992). Regions encoded by different exons are distinguished by gray and black color. Numbers indicate the corresponding exons shown in $A$. Three variants of the amino terminal sequence of GlyT1 (hatched) originate from exons 1a, 1b, and $1 \mathrm{c}$.

et al., 1990). The only exception from this rule is exon 8 , which encodes two putative transmembrane domains. Interestingly, in the GAT1 gene the corresponding region is split by an additional intron, which separates these transmembrane regions.

\section{Analysis of GlyT1 cDNA 5'-ends and identification of two separate promoters}

To understand the mechanism generating the different 5 '-ends of the GlyT1 mRNAs, rapid amplification of cDNA 5 '-ends (RACE) was performed. After two rounds of amplification with nested primers we obtained two major bands from PCR reactions with a primer common for GlyT1a and $1 \mathrm{~b}$ and a single band with a GlyT1b-specific primer (data not shown). Subcloning and sequencing of these products revealed that the noncoding sequences at the $5^{\prime}$-ends of the $1 \mathrm{a}$ and $1 \mathrm{~b} / 1 \mathrm{c}$ isoforms are completcly different, and that they do not share any common exons in addition to exons $2-13$ (Fig. 2). The GlyT1a mRNA is generated by splicing the 5 -specific exons 0a, 1a to the common exons $2-13$, whereas the $5^{\prime}$-end of the GlyT1b transcript is con- 
Table 2. Size and junction sequences of the introns in the mouse GlyT1 gene

\begin{tabular}{llll} 
Intron between & 5'-Junction sequence & 3'-Junction sequence & Size $(\mathrm{kb})$ \\
\hline $0 \mathrm{a}-1 \mathrm{a}$ & AGTATGgtaga & ccacagCTCTTG & 1.0 \\
$1 \mathrm{a}-1 \mathrm{~b}$ & ATGTTGgtgagt & ctccagCTCCGG & 2.7 \\
$1 \mathrm{~b}-1 \mathrm{c}$ & GAACAGglcagc & & 5.8 \\
$1 \mathrm{c}-2$ & GCTCAGgtcagc & ccacagAATGGT & 0.6 \\
$2-3$ & GGGGAGgtaccc & tgccagGAGCCT & 0.8 \\
$3-4$ & TCAAAGgtgagg & ccacagGCGTGG & 0.4 \\
$4-5$ & CTGGAGgtgagg & ccccagGCTGTA & 0.8 \\
$5-6$ & GGGAAAgcaagt & tcccagGTGGTG & 0.1 \\
$6-7$ & GCCAAGgtggga & ctgcagGTCTGG & 0.1 \\
$7-8$ & CTACCGgtgagt & cctcagGGACAG & 0.5 \\
$8-9$ & ACTCAGgtatgg & ctgtagTTCTGC & 0.1 \\
$9-10$ & AGCCAGgtaaga & ccacagGCAGGC & 0.1 \\
$10-11$ & TCTATGgtgagt & ctccagGGCACC & 0.1 \\
$11-12$ & ATCTTTgtaagt & ctctagTTCATT & 2.1 \\
$12-13$ & CTTCAGgtgagg & ctgcagCGTTTG & 0.1
\end{tabular}

Positions of the introns are indicated in Figure $1 \mathrm{~A}$. Exon sequences are typed in uppercase letters, and intron sequences in lowercase letters. The $5^{\prime}$-junction sequence of exon $1 \mathrm{c}$ in mouse has not been identified, because its $5^{\prime}$ end lacks homology to the human counterpart (Kim et al., 1994). With one exception all splice sites (boldface) follow the "GT/ AG" rule; an unusual GC at the beginning of the 5'-donor splice site has been reported (Amin et al., 1993).

tained in a single exon (1b). The third isoform GlyT1c is generated by alternative splicing of a common $1 \mathrm{~b}$ pre-mRNA (Fig. $1 B$ ). Exons $1 \mathrm{~b}$ and $1 \mathrm{c}$ have been reported to precede the common part of the GlyT1 mRNAs encoded by exons 2-13 in humans (Kim et al., 1994). A putative exon 1c revealing $73 \%$ amino acid identity and $78 \%$ homology to its human counterpart was present in the subclones sequenced (Fig. 2). However, only 120 bp showed a clear homology to the human sequences. No sequences homologous to the remaining 36 bp could be identified.

We obtained several clones with different 5 '-ends, some of which contained an additional 5 '-terminal $G$ residue not present in the genomic sequence. This is a typical artefact generated by reverse transcription of the 5 '-cap-G structure (Hirzmann et al., 1993), and thus allows an unambiguous identification of transcriptional startpoints. By this approach at least four different startpoints were identified from the sequence of 23 clones for GlyT1b (Fig. 2), but a much larger number of startpoints probably exists as indicated by the high diversity of RACE products. Eight clones specific for GlyTla were sequenced, but a similar variety of $5^{\prime}$ ends was observed (see Fig. 2 caption). Additional sequences included in the GlyT1a mRNA population were identificd by PCR of mouse brain cDNA with different sense primers derived from the genomic sequence (Fig. 2). In conclusion, our sequence data prove that the mRNA isoforms GlyT1a and 1b/ $1 \mathrm{c}$ originate from initiation of transcription from different promoters, and that startpoints for both primary transcripts are scattered over a region of about $150 \mathrm{bp}$. It remains unclear why only a single band for all GlyT1 mRNA isoforms was observed in Northern hybridization experiments (Borowsky et al., 1993; Kim et al., 1994), whereas differences in size of about $350 \mathrm{bp}$ would be expected from our analysis of cDNA 5 '-ends.

Analysis of the regions upstream of the GlyTla and GlyT1b transcription startpoints identified high GC contents $(60 \%)$ and several potential Spl binding sites (Jones et al., 1985) preceding exon 0 a.

\section{Expression of GlyTI mRNAs during embryonic development}

Expression of the murine GlyT1 gene during embryonic development was analyzed by a RNase protection assay. A 450 bp fragment corresponding to sequences from exons $0 \mathrm{a}, 1 \mathrm{a}$, and $2-$ 5 of the GlyT1a cDNA clone (Fig. $3 A$ ) was used as a template to synthesize a ${ }^{33} \mathrm{P}$-labeled antisense RNA probe. A $258 \mathrm{bp}$ fragment of the $\beta$-tubulin 5 cDNA (Wang et al., 1986; provided by R. Balling) was used in addition as an internal control for comparable RNA amounts. A mixture of both probes was annealed with total RNA isolated from E9 to E17 mouse embryos, and with RNA from adult mouse brain and liver (Fig. $3 B$ ). A fragment corresponding to the expected length of the GlyT1a sequence was detected in every sample with the exception of the yeast control RNA. In addition a shorter fragment corresponding in length to the sequence shared by all variants was observed; this fragment corresponds to the Glyt1b/c mRNA protected sequence. Weak signals for GlyT1a and the GlyT1b/c variants were observed even at the earliest stages of embryonic development analyzed (E9, E10). Maximal levels of GlyT1 transcripts were found at embryonic stages E13 to E15. Both protected fragments were also obtained with adult brain and liver RNA. The latter result is in disagreement to a Northern blot analysis published by Borowsky et al. (1993), who found Gly'T1b mRNAs only in the CNS. Our results were corroborated by Northern blot hybridization which showed strong expression only in brain and liver and weak expression in lung and kidney (Fig. $3 C$ ).

\section{Distribution of glycine transporter GlyT1 and GlyT2 mRNAs}

The spatial pattern of GlyT1 expression in the developing mouse embryo was analyzed by in situ hybridization with ${ }^{35} \mathrm{~S}$-labeled antisense RNA probes and compared to that of GlyT2, and the inhibitory glycine receptor subunit genes GlyR $\alpha 1$, GlyR $\alpha 2$, and GlyR $\beta$. Three different probes for GlyT1 were tested. The best results were obtained with probe GlyT1a/b which encompasses the complete coding sequence of GlyT1 and detects all variants. Probes specific for GlyT1a or GlyT1b gave no signal above background, presumably because of their relatively small size.

GlyT1 mRNAs were first detected in the spinal cord at E11 in the ventral part of the ventricular zone which contains the proliferating precursors of neurons and glia (Fig. 4A). At E12 the GlyT1 signal in the ventricular zone was more pronounced 


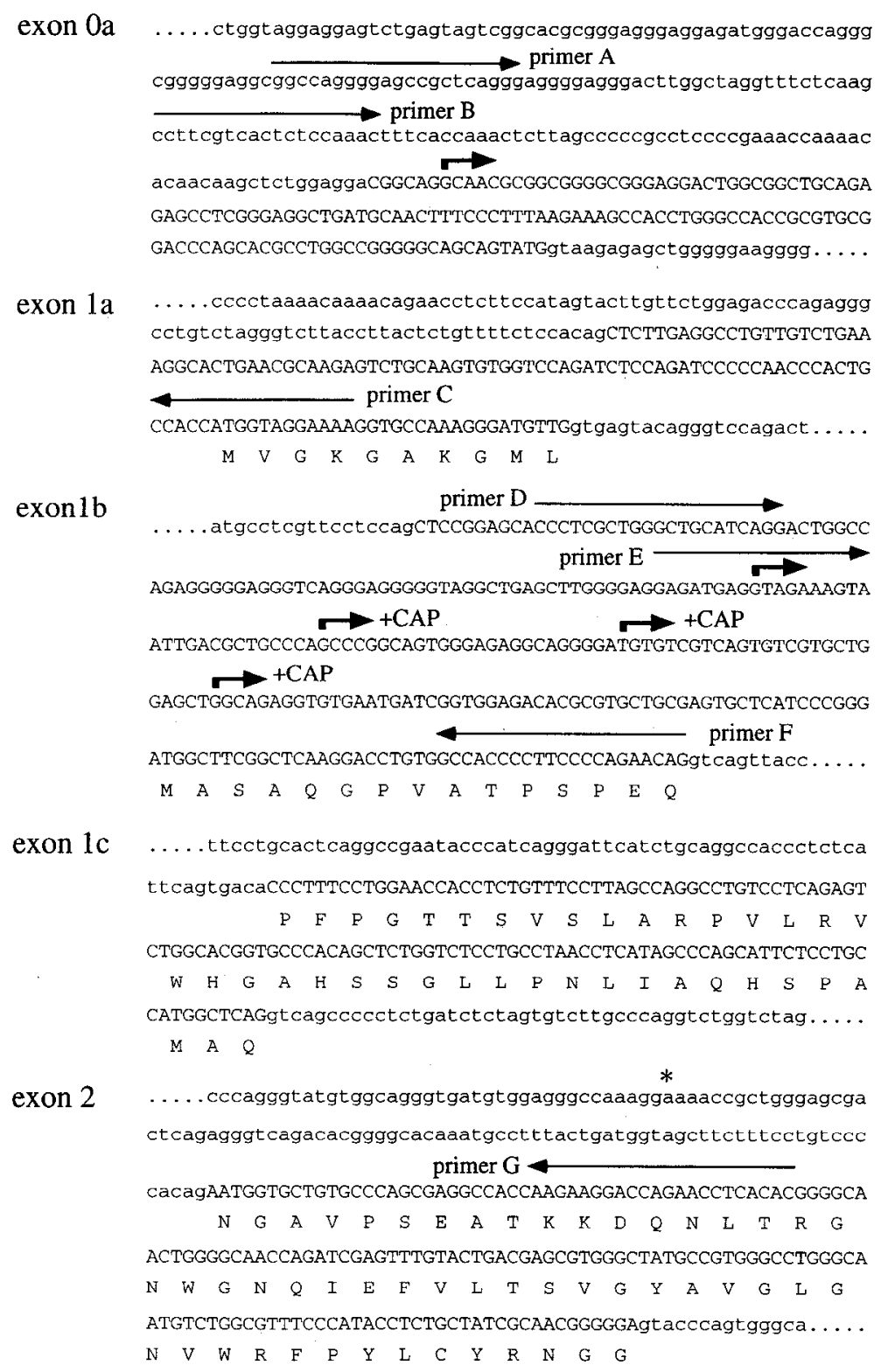

Figure 2. Analysis of GlyT1 cDNA 5'-ends and identification of two separate promoters. The structures of exons $1 \mathrm{a}, 1 \mathrm{~b}$, and 2 as proposed by Liu et al. (1993b) and the 5'-end of the GlyT1a cDNA (exon 0a; see Liu et al., 1992b) are indicated in uppercase (exons) and lowercase (introns) letters. Only a partial sequence of a putative exon (1c) homologous to the human GlyT1c (Kim et al., 1994) is shown in uppercase. The $5^{\prime}$ end of the mouse sequence could not be identified by comparison to its human counterpart. Different 5 '-ends of clones generated by RACE experiments indicate the existence of several startpoints of transcription. The most 5'-located initiation sites including those containing an uncoded $5^{\prime}$-terminal $\mathrm{G}$ residue caused by reverse transcription of the 5'-cap-G structure (marked by $+C A P$ ) are indicated by thick arrows. Multiple startpoints of transcription preceding exon $1 \mathrm{~b}$ prove that the GlyTla and $\mathrm{lb}$ isoforms originate from two separate promoters. A potential splice junction in front of exon $1 \mathrm{~b}$ predicted by computer analysis (Liu et al., 1993b) appears not to be used, since PCR of randomly primed cDNA with primers D and F (marked by arrows above the sequence) yielded no product. In contrast, a specific product was obtained with primers $\mathrm{E}$ and $\mathrm{F}$, although the sense primer shows only a partial overlap with the longest RACE clone analyzed. PCR analysis with primers A or B (sense) and C (antisense) gave specific products and additional sequence information about the $5^{\prime}$ ends of the GlyTla mRNA. In contrast, a sense primer positioned 150 bp upstream from primer A for PCR, yielded no product. Only GlyT1a-specific products resulted from PCR with primers A (or B) and G, and Southern hybridization (data not shown) failed to detect GlyT1b-specific product from this reaction. This demonstrates that no splice product of exons $0 \mathrm{a}$ and $1 \mathrm{~b}$ is generated. An unexpected RACE clone amplified with the anchor primer and primer $\mathrm{G}$ included $87 \mathrm{bp}$ of the intronic sequence upstream of exon 2 at its 5 '-end (marked by asterisk) and probably reflects aberrant splicing. In our analysis, no clones corresponding to the GlyTlc variant were obtained.

(Fig. 4B). At E15 GlyT1 transcripts were also detected in the adjacent ventral mantle zone and the meninges surrounding the spinal cord (Fig. 1C). A strong signal for GlyT1 was also obtained in liver in sagittal sections of E12 and E15 embryos (data not shown), consistent with data showing GlyT1a expression in adult liver (Borowsky et al., 1993). Other embryonic tissues did not show significant hybridization signals.
Expression of GlyT2 was detected as early as E11 in the intermediate position of the mantle zone directly adjacent to the ventricular zone (Fig. 4D). At E12 expression in this region was still visible, but additional signals were observed in the basal and alar plates (Fig. $4 E$ ). These regions do not express GlyT1, but contain postmitotic neural precursors. At E15 GlyT2 transcripts were seen preferentially in the ventral horn of the gray 
A

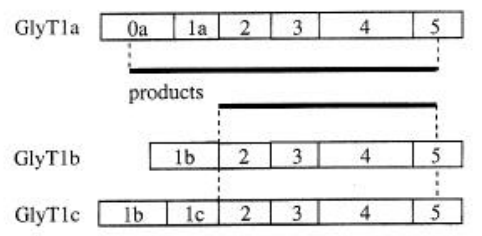

B

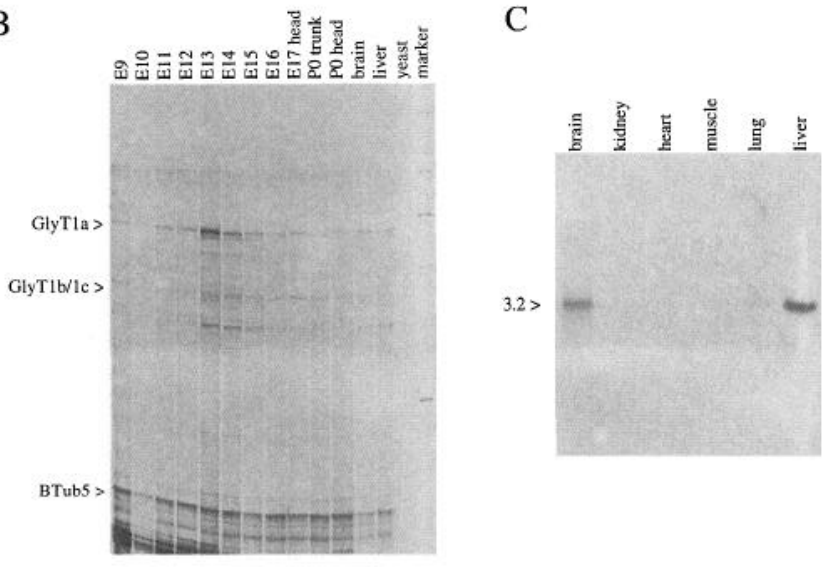

Figure 3. Accumulation of GlyT1 transcripts in the developing mouse embryo and distribution in several tissues of adult rats. A, Schematic representation of the products (solid bars) generated by RNase protection of an GlyTla-specific antisense RNA probe with GlyT1a or 1b/1c mRNAs. Exons are indicated by numbered boxes. B,Total RNA isolated from whole embryos at different embryonic stages (E9-E16), from heads or trunks at days E17 and P0, and from adult brain or liver, was analyzed by RNase protection assay using ${ }^{33} \mathrm{P}$-labeled probes for the GlyT1 a ( 450 bases) and $\beta$-tubulin 5 (BTub5, 258 bases) mRNAs. Bands corresponding to the transcripts (arrows) GlyT1a and 1b/1c were observed as early as E9 and reached maximal levels between E13 and E15. Additionally both mRNAs were detectable in adult brain and liver, but not in a control sample (yeast total RNA). The presence of similar amounts of RNA in all samples was demonstrated by the product obtained with the BTub5 probe. Sizes of DNA marker fragments (Boehringer Mannheim) are 653,517, 453, 394, and 298 bp. C, Distribution of GlyT1 mRNAs in several tissues of adult rats. PolyA ${ }^{+}$RNA from brain, kidney, heart, muscle, lung, and liver was hybridized with a probe recognizing all Glyt1 mRNA variants. Strong signals of about $3.2 \mathrm{ki}-$ lobases were obtained for brain and liver, whereas a weak band of the same size was visible for lung. Transcript size is indicated in kilobases.

matter (Fig. 4F), with lower levels in intermediate layers and absent from the dorsal horn.

To compare the sites of glycine transporter expression to regions synthesizing the postsynaptic glycine receptors we also hybridized embryonic sections to probes specific for different glycine receptor subunits. GlyR $\alpha 2$ is the first glycine receptor subunit to be expressed during embryonic development (Kuhse et al., 1990; Malosio et al., 1991; Sato et al., 1992). Here transcripts were seen first at E12 in the lateral parts of the ventral horn, where motor neurons are located (Fig. 4H). At E15 GlyR $\alpha 2$ transcripts were seen predominantly in the ventral horn, with some expression in more dorsal layers (Fig. $4 H$ ); this pattern resembles that seen with the GlyT2 probe. In agreement with earlier reports (Malosio et al., 1991) expression of the GlyR $\alpha 1$ and GlyR $\beta$ mRNA was detectable throughout the gray matter in E15 spinal cord, but not at earlier stages (data not shown). Low levels of GlyR $\beta$ mRNA were in addition seen in dorsal root ganglia (data not shown).

\section{GlyT1 is expressed in glial cells}

To more precisely determine the cell types expressing GlyT1 we performed in situ hybridization with sections of adult rat brain and spinal cord, which allow an easier identification of cell types according to morphological and anatomical criteria. By using two GlyT1-specific antisense oligonucleotide probes derived from the rat GlyT1a cDNA (Smith et al., 1992), the regional expression of GlyT1 mRNAs was investigated. In general, positive cells were distributed throughout the CNS and detectable in both gray and white matter (Fig. $5 A, C, E, G$ ). In the gray matter cells containing GlyT1 transcripts were small-sized and neurons were devoid of hybridization signals (Fig. $5 B$ ), suggesting that the positive cells are of glial origin.

In the spinal cord (Fig. 5A) positive cells were observed not only in the gray, but also in the white matter. At higher magnification hybridization signals were mainly seen over small-sized cells surrounding motor neurons, whereas neurons did not show any signal (Fig. $5 B$ ). In the cerebellum expression of GlyT1 was mainly observed in the white matter and in the Purkinje cell layer (Fig. 5C). Silver grains were absent over Purkinje cell bodies (Fig. $5 D$ ) but many small cells surrounding the Purkinje cells exhibited strong hybridization signals. From their anatomical appearance the positive cells are likely to be Bergmann glia, a specialized class of astrocytes. The level of GlyT1 expression in hippocampus and cerebral cortex (Fig. 5E,F) is relatively low in contrast to the corpus callosum, which contains a large number of strongly labeled cells. However, both regions showed small-sized positive cells expressing GlyT1 mRNAs at low levels. Granule cells in the dentate gyrus and pyramidal cells in the Ammon's horn did not express GlyT1 transcripts but many small labeled cells were observed throughout the hippocampus. The optic nerve also contained a large number of strongly labeled cells (Fig. 5G,H). Since there are no neuronal cell bodies in this structure, it is obvious that glial cells express the GlyT1 mRNAs.

\section{Discussion}

Genomic structure of the glycine transporter 1 gene and generation of $M R N A$ variants

We determined the genomic structure of the GlyT1 gene in order to understand the origin of the different transporter isoforms and the genetic basis of their regulation. The genomic organization of the GlyT1 gene is very similar to that of GAT1 (Liu et al., 1992a). It has been hypothesized that the transmembrane regions, which are highly conserved among different members of the transporter family, form a "core" transporter, whereas the extra- and intracellular loops as well as the amino- and carboxy-terminal regions are responsible for specific properties, such as substrate selectivity and regulation (Clark et al., 1992; Fremeau et al., 1992; Mabjeesh et al., 1992). This seems to be reflected in the genomic structure of the GlyT1 and GAT1 genes (Liu et al., 1992a). In both genes most transmembrane segments are encoded by single exons, and most splice site positions and sequences are highly conserved. The only exceptions are transmembrane segments 7 and 8 of GlyT1 which are encoded by a single exon but by separate exons in the GAT1 gene. In addition, the coding sequence of the second large extracellular loop in GAT1 is divided into two exons in contrast to the single exon 4 that encodes the corresponding sequence in GlyT1. Interestingly, the amino acid sequence of the first half of this loop is highly conserved between both transporters, whereas the second part, which is encoded by a separate exon in GAT1, strongly differs in its length and sequence. In 
Figure 4. Comparative in situ hybridization analysis of GlyT1, GlyT2, and GlyR $\alpha 2$ transcripts in the developing mouse spinal cord. Sections of embryonic spinal cord at three different stages, E11 $(A, D, G), \mathrm{E} 12(B, E, H)$, and $\mathrm{E} 15(C, F, I)$, were hybridized to probes for GlyT1 $(A-C)$, GlyT2 $(D-F)$, and GlyR $\alpha 2(G-I)$. A, At E11 GlyT1 (A) transcripts were detected in the ventral part of the ventricular zone, and labeling was increased at E12 $(B) . C$, At E15 GlyT1 was detected in the adjacent mantle zone and in the meninges. $D$, Expression of GlyT2 was as early as E11 seen in the intermediate position of the mantle zone. $E$, Note that GlyT2 signals at E12 do not overlap regions expressing GlyT1. $F$, At E15 GlyT2 transcript were seen throughout the spinal cord, but mainly in the ventral horn of gray matter. $H$, GlyR $\alpha 2$ mRNA was first detected at E12 in lateral parts of the ventral horn, whereas no signals were visible at E11 $(G)$. $I$, At E15 transcript for the GlyR $\alpha 2$ expression predominated in the ventral horn. $v$, Ventricular zone; $m$ mantle zone; me, meninges; $d h$, dorsal horn; $v h$, ventral horn. Scale bars: $A, B$, $D, E, G$, and $H, 200 \mu \mathrm{m} ; C, F$, and $I$, $400 \mu \mathrm{m}$.
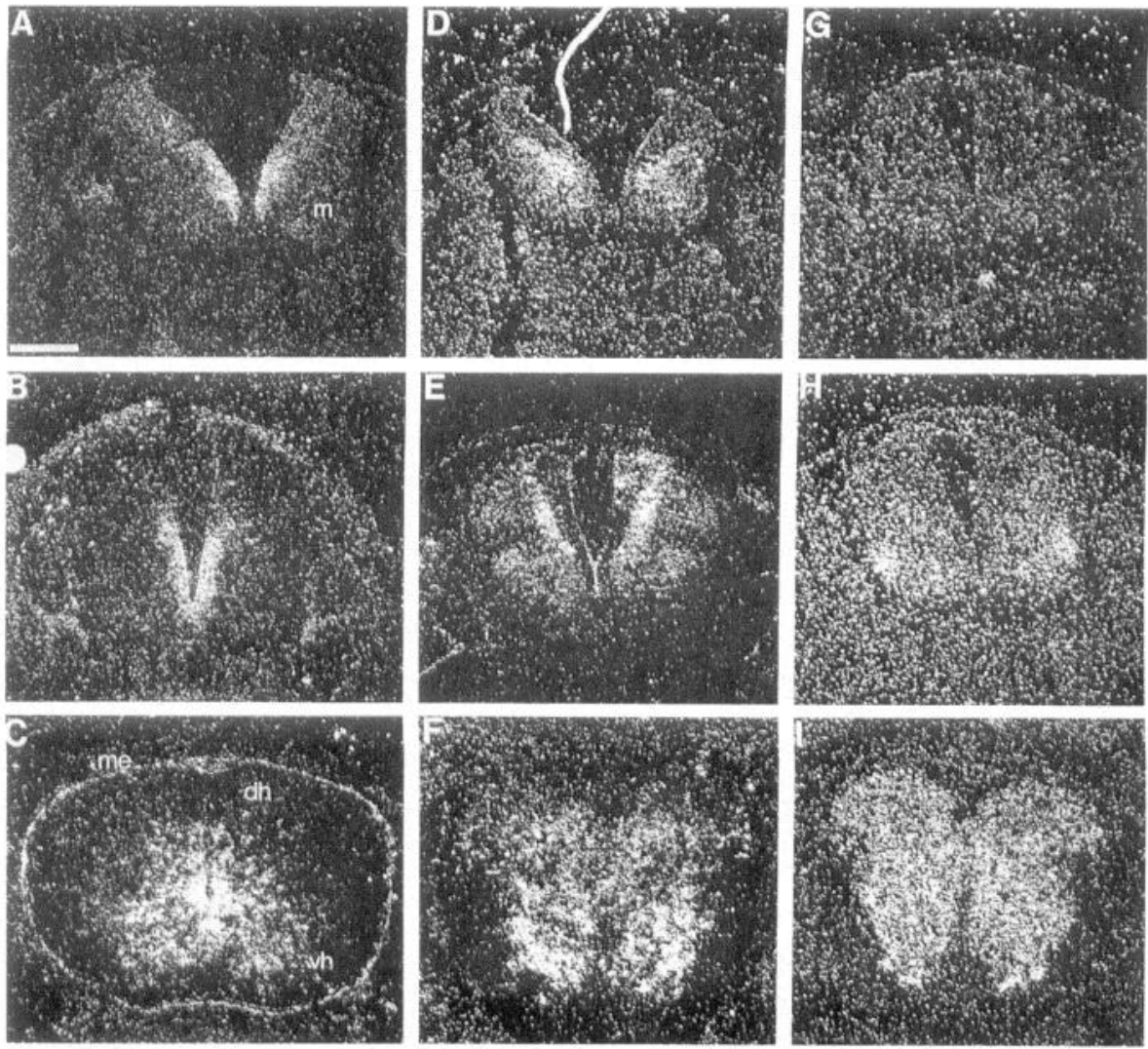

contrast to the transmembrane segments, the sequences of the amino- and carboxy-terminal ends, encoded by exons 1 and 13, of GlyT1 show very little homology to GAT1. Also, the sequence variants for the amino terminus of GlyT1 are unrelated to GAT1. Accordingly, the genomic structure of the $5^{\prime}$-ends of both genes differs greatly.

So far it remained unclear whether different GlyT1 isoforms arise from the use of different promoters or by alternative splicing of a common pre-mRNA. Our data clearly demonstrate that the mRNAs for the two variants GlyTla and $1 b$ are generated from two different promoters in front of exons $0 \mathrm{a}$ and $\mathrm{lb}$, and that both promoters use multiple transcriptional startpoints and lack TATAboxes. Multiple startpoints of transcription have been reported for many genes lacking TATA-boxes (Harlan et al., 1991; Ma et al., $1992)$ and, together with a high GC content $(60 \%$ in the GlyT1 gene), are characteristic for promoters of many housekeeping genes (Smale et al., 1989; Harlan et al., 1991). Analysis of the two promoters in the GlyT1 gene should reveal genetic elements responsible for the differential expression of the isoforms.

\section{Expression of glycine transporters and glycine receptor subunits} in the developing embryonic spinal cord of mouse

The mRNAs for the glycine transporter variants GlyT1a and 1b/ 1c are present at low levels as early as E9 and E10 as determined by RNase protection assays, but strongly increase at stage E13 and remain at high levels up to E15. As the RNase protection assays were done with RNA from whole embryos, these results do not provide a spatial resolution. Therefore, the distribution of GlyT1 and GlyT2 transcripts in the developing mouse spinal cord was analyzed by in situ hybridization. Consistent with the time course of expression shown by RNase protection assays, specific mRNAs could be detected at early stages. Strong signals with both GlyT1 and GlyT2 probes are first seen at E11 in nonoverlapping domains. The expression of glycine transporter genes and GlyR $\alpha 2$ (see below) is activated much earlier than formation of synapses in the spinal cord has been observed (Vaughn et al., 1973; May et al., 1975), indicating that cells generating a glycinergic synapse possess a neurochemical identity early in development. The expression of GlyT1 is limited to the ventral part of the ventricular zone, which contains precursors of neurons and glial cells (Nornes et al., 1974, 1978). GlyT2 expression was observed at an intermediate position in the mantle zone. At E12 the GlyT1 expression domain is unchanged, but GlyT2 transcripts are more widely distributed with the highest levels in the medial part of the mantle zone. Thus, at this stage GlyT1 mRNAs are found exclusively in proliferating cells, whereas the message for GlyT2 is limited to postmitotic cells (Altman et al., 1984). The expression domains start to overlap only at E15. Now, signals specific for GlyT1 increased in the ventral part of the ventricular zone and in addition were detected in the medial half of the basal and intermediate gray matter. GlyT2 is expressed preferentially throughout the ventral horns and excluded from the dorsal horn at this stage. The expression pattern of GlyT1 at E15 is similar to genes expressed specifically in glia (Feng et al., 1994), whereas that of GlyT2 is more reminiscent of a neuronal expression. Motor neurons receive inhibitory glycinergic innervation from spinal cord interneurons, which should express glycine transporters. GlyT2 transcripts are found in regions containing more ventrally located commissural interneurons and association interneurons. GlyT1 expression is also seen in the meninges at E15, indicating that the latter might be involved in a more general control of glycine concentration in the CNS.

Glycine is the major inhibitory neurotransmitter in spinal cord, brain stem and other areas of the lower neuraxis of mam- 


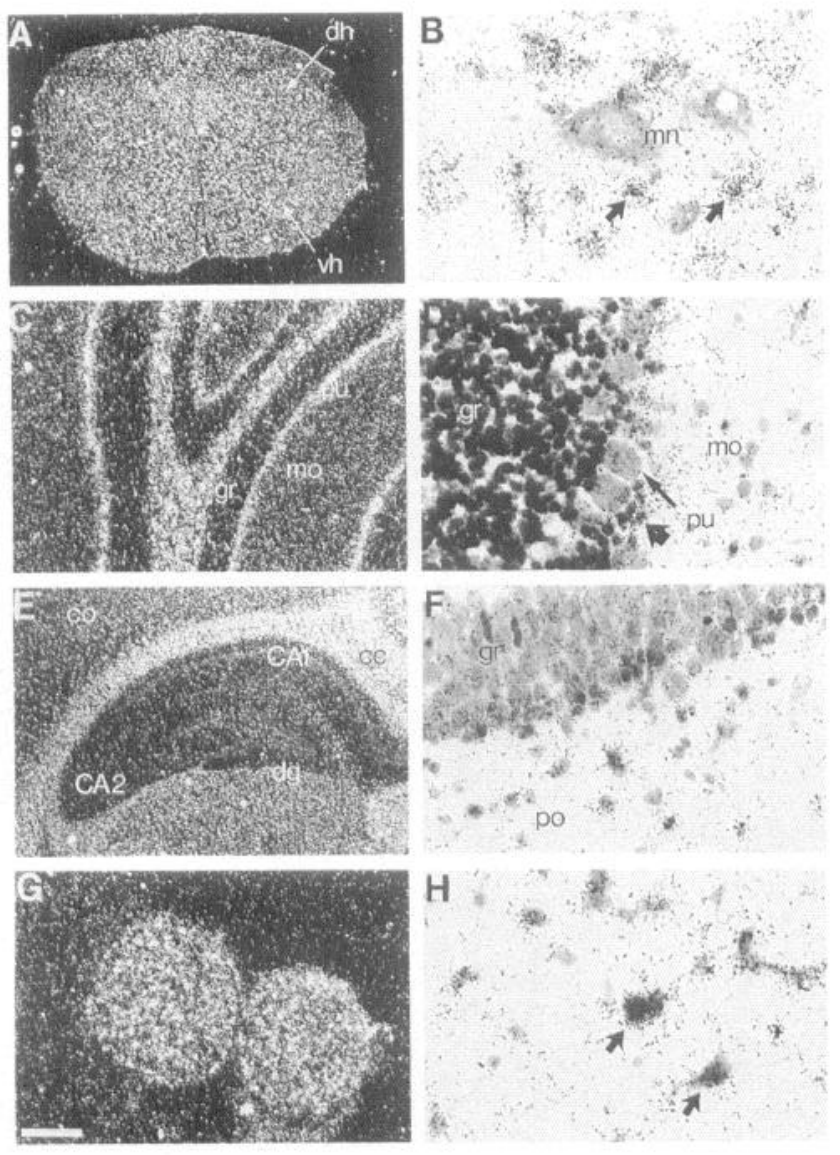

Figure 5. Distribution of GlyT1 mRNAs in the adult rat brain. Low magnification dark-field images $(A, C, E, G)$ and high magnification bright-field images of counterstained sections $(B, D, F, H)$ of the spinal cord $(A, B)$, cerebellum $(C, D)$, hippocampus $(E, F)$, and optic nerve $(G, H)$ hybridized with ${ }^{35} \mathrm{~S}$-labeled oligonucleotide probes are shown. $A$, Positive cells were detectable throughout the gray and the white matter. $B$, A motor neuron $(\mathrm{mn})$ was devoid of a hybridization signal, but many small-sized positive cells displayed strong hybridization (arrows). $C$, Expression of GlyT1 in the cerebellum was mainly observed in the white matter and in the Purkinje cell layer $(p u), D$, Bergmann glia cells (thick arrow) adjacent to Purkinje cells ( $p u$, thin arrow) showed intense hybridization. $E$, Note strong expression of GlyT1 mRNAs in the corpus callosum $(c c)$. $F$, Granule cells in the dentate gyrus $(\mathrm{gr})$ were devoid of signals, in contrast to many small-sized cells in the polymorphic layer (po). $G$, High levels of GlyT1 mRNAs were detected in the optic nerve. $H$, Many cells in the optic nerve were labeled (arrows). $d h$ and $v h$, dorsal and ventral horn of spinal cord; $g r$, granule cell layer of cerebellum $(C, D)$, and stratum granulare of the dentate gyrus $(F)$; mo, molecular layer of cerebellum; $C A 1-2$, fields CA1-2 of Ammon's horn; $c o$, cortex. Scale bar: $A, 800 \mu \mathrm{m} ; B$ and $F$, $32 \mu \mathrm{m} ; C$ and $E, 200 \mu \mathrm{m} ; H, 20 \mu \mathrm{m}$.

mals (Aprison et al., 1990). Glycine-mediated inhibition of neuronal activity results from activation of the inhibitory glycine receptor (GlyR), a ligand gated chloride channel. The GlyR is thought to be a pentamer composed of ligand binding $\alpha$-subunits and structural $\beta$-subunits. Several developmentally regulated $\alpha$ subunit variants have been described which correspond to neonatal $(\alpha 2)$ and adult $(\alpha 1, \alpha 3)$ GlyR isoforms (Betz, 1992). Expression of the $\alpha 2$ and $\beta$ GlyR subunits has been found as early as E14 in rat (Malosio et al., 1991). Here we analyzed the expression of these subunits in mouse embryos starting at E11 to identify the earliest time when the embryonal nervous system activates these genes. We first detected expression of GlyR $\alpha 2$ at
E12 which is about 1-2 d earlier than described previously (Malosio et al., 1991). Expression was seen in a small population of cells at a ventrolateral position where motor neurons are located. At this stage none of the other subunit genes was expressed. At E15 transcripts of all GlyR subunits analyzed were found. GlyR $\alpha 1$ and $\beta$ mRNAs were uniformly distributed in the spinal cord, whereas GlyR $\alpha 2$ transcripts were found predominantly in the ventral horn, suggesting their localization in motor neurons. Consistent with an earlier study (Furuyama et al., 1992), GlyR $\beta$ mRNA was also seen at low levels in dorsal root ganglia.

\section{The glycine transporter GlyT1 is expressed in glial cells}

The distribution of GlyT1 mRNA in different tissues has been investigated by several groups both by Northern blot analysis and in situ hybridization (Guastella et al., 1992; Smith et al., 1992; Borowsky et al., 1993; Kim et al., 1994). Unfortunately, the results of these studies are contradictory. Whereas Kim et al. (1994) reported expression in all non-neuronal tissues analyzed, including kidney and liver, Liu et al. (1993), Guastella et al. (1992), and Smith et al. (1992) failed to detect significant amounts of GlyT1 mRNA in liver. Our data show strong expression of GlyT1 in liver both by an RNase protection assay and by Northern blots (Fig. $3 C$ ). These discrepancies might be due to the different probes and hybridization conditions used.

Smith et al. (1992) and Borowsky et al. (1993) reported strong to moderate expression in the pyramidal cell layer of the CA13 and the granule cell layer of the dentate gyrus in the hippocampus, while Guastella et al. (1992) found no hybridization in this region. Furthermore, Borowsky et al. observed strong signals in all fiber tracts, while the other two articles reported no expression. These discrepancies could be due to nonstringent hybridization conditions as well as low-resolution autoradiography. Here, we investigated the expression of GlyT1 mRNA at the cellular level by using rat brain sections. Many positive cells were observed not only in the gray but also in the white matter. Usually the labeled cells were of small size and showed a similar appearance in both regions. All neurons seemed to be devoid of labeling throughout the CNS regions analyzed. For example, in the hippocampus neither pyramidal cells in the CA1-3 nor granule cells in the dentate gyrus showed positive hybridization signals. Furthermore, in the cerebellar cortex only glial cells showed strong expression. Borowsky et al. (1993) reported that GlyT1a mRNA was mainly expressed in white matter, whereas GlyT1b mRNA was abundant in gray matter. These authors therefore suggested that GlyT1a may be a neuronal and GlyT1b a glial glycine transporter. However, our probes, although they recognized all GlyT1 mRNA isoforms, failed to reveal positive neurons throughout the CNS. Thus, we conclude that both GlyT1a and GlyT1b/1c are mainly or exclusively expressed in glial cells. However, our data cannot exclude expression of GlyT1 by a subpopulation of neurons or in tissues not analyzed in this study. The previously published data are consistent with the view that glial cells in the white matter express mainly GlyT1a and glial cells in the gray matter mainly GlyT1b, respectively.

\section{Note added in proof}

The nucleotide sequence data in this article will appear in the EMBL, GenBank, and DDBJ Nucleotide Sequence Databases under accession numbers X82566-X82572. 


\section{References}

Altman J, Bayer SA (1984) The development of the rat spinal cord. Adv Anat Cell Biol 85.

Amin KM, Scarpa AL, Winkelmann JC, Curtis PJ, Forget BG (1993) The exon-intron organization of the human erythroid beta-spectrin gene. Genomics 18:118-125.

Aprison MH (1990) The discovery of the neurotransmitter role of glycine. In: Glycine transmission (Ottersen OP, Storm-Mathiesen J, eds). New York: Wiley.

Attwell D, Bouvier M (1992) Cloners quick on the uptake. Curr Biol $2: 541-543$

Attwell D, Barbour B, Szatkowski M (1993) Nonvesicular release of neurotransmitter. Neuron 11:401-407.

Betz H (1992) Structure and function of inhibitory glycine receptors. Q Rev Biophys 25:381-394.

Blakely RD, Bersen HE, Fremeau RT Jr, Caron MG, Peek MM, Prince HK, Bradley CC (1991) Cloning and expression of a functional serotonin transporter from rat brain. Nature 354:66-70.

Borowsky B, Mezey É, Hoffman BJ (1993) Two glycine transporter variants with distinct localization in the CNS and peripheral tissues are encoded by a common gene. Neuron 10:851-863.

Chirgwin JM, Prybyla AE, MacDanold RJ, Rutter WJ (1979) Isolation of biologically active ribonucleic acid from sources enriched in ribonuclease. Biochemistry 18:5294-5299.

Clark JA, Deutch AY, Gallipoli PZ, Amara SG (1992) Functional expression and CNS distribution of a $\beta$-alanine-sensitive neuronal GABA transporter. Neuron 9:337-348.

Dorit RL, Schoenbach L, Gilbert W (1990) How big is the universe of exons? Science 250:1377-1382.

Feng L, Hatten ME, Heintz N (1994) Brain lipid-binding protein (BLBP): a novel signaling system in the developing mammalian CNS. Neuron 12:895-908.

Fremeau RT Jr, Caron MG, Blakely RD (1992) Molecular cloning of a high affinity L-proline transporter expressed in putative glutaminergic pathways of rat brain. Ncuron 8:915-926.

Furuyama T, Sato M, Sato K, Araki T, Inagaki S, Tagaki H, Tohyama M (1992) Co-expression of glycine receptor $\beta$ subunit and $\mathrm{GABA}_{\mathrm{A}}$ receptor $\gamma$ subunit mRNA in rat dorsal root ganglion cells. Mol Brain Res 12:335-338.

Giros B, El Mestikawy S, Bertrand L, Caron MG (1991) Cloning and functional characterization of a cocaine-sensitive dopamine transporter. FEBS Lett 295:149-154.

Guastella J, Nelson N, Nelson H, Czyzyk L, Keynan S, Miedel MC, Davidson N, Lester HA, Kanner BI (1990) Cloning and expression of a rat brain GABA transporter. Science 249:1303-1306.

Guastella J, Brecha N, Weigmann C., Lester H, Davidson N (1992) Cloning, expression, and localization of a rat-brain high-affinity glycine transporter. Proc Natl Acad Sci USA 89:7189-7193.

Harlan DM, Graff JM, Stumpo DJ, Eddy RL Jr, Shows TB, Boyle JM, Blackshear PJ (1991) The human myristoylated alanine-rich C kinase substrate (MARCKS) gene (MACS). J Biol Chem 266:14399-14405.

Hirzmann J, Luo D, Hahnen J, Hobom G (1993) Determination of messenger RNA 5 -ends by reverse transcription of the cap structure. Nucleic Acids Res 21:3597-3598.

Hoffman BJ, Mezey E, Brownstein MJ (1991) Cloning of a serotonin transporter affected by antidepressants. Science 254:579-580.

Johnson JW, Ascher P (1987) Glycine potentiates the NMDA response in cultured mouse brain neurons. Nature 325:529-531.

Jones KA, Tjian R (1985) Sp1 binds to promoter sequences and activates herpes simplex virus 'immediate-early' gene transcription in vitro. Nature 317:179-182.

Kilty J, Lorang D, Amara SG (1991) Cloning and expression of a cocaine-sensitive rat dopamine transporter. Science 254:578 579.

Kim K-M, Kingsmore SF, Han H, Yang-Feng TL, Godinot N, Seldin MF, Caron MG, Giros B (1994) Cloning of the human glycine transporter type 1: molecular and phannacological characterization of novel isoform variants and chromosomal localization of the gene in the human and mouse genomes. Mol Pharmacol 45:608-617.

Kuhse J, Schmieden V, Betz H (1990) A single amino acid exchange alters the pharmacology of neonatal rat glycine receptor subunit. Neuron 5:867-873.

Kuryatov A, Laube B, Betz H, Kuhse J (1994) Mutational analysis of the glycine-binding site of the NMDA receptor: structural similarity with hacterial amino acid-binding proteins. Neuron 12:1291-1300.

Liu Q-R, Mandiyan S, Nelson H, Nelson N (1992a) A family of genes encoding neurotransmitter transporters. Proc Natl Acad Sci USA 89: 6639-6643.

Liu Q-R, Nelson H, Mandiyan S, López-Corcuera B, Nelson N (1992b) Cloning and expression of a glycine transporter from mouse brain. FEBS Lett 305:110-114.

Liu Q-R, López-Corcuera B, Mandiyan S, Nelson H, Nelson N (1993a) Molecular characterization of four pharmacologically distinct $\gamma$-aminobutyric acid transporters in mouse brain. J Biol Chem 268:21062112.

Liu Q-R, López-Corcuera B, Mandiyan S, Nelson H, Nelson N (1993b) Cloning and expression of a spinal cord- and brain-specific glycine transporter with novel structural features. J Biol Chem 268:2280222808.

López-Corcuera B, Liu Q-R, Mandiyan S, Nelson H, Nelson N (1992) Expression of a mouse brain cDNA encoding a novel $\gamma$-aminobutyric acid transporter. J Biol Chem 267:17491-17493.

Ma L, Weeda G, Jochemsen AG, Bootsma D, Hoeijmakers, van der Eb AJ (1991) Molecular and functional analysis of the XPBC/ERCC-3 promoter: transcription activity is dependent on the integrity of an SP1binding site. Nucleic Acid Res 20:217-224.

Mabjeesh NJ, Kanner BI (1992) Neither amino or carboxyl termini are required for function of the sodium- and chloride-coupled $\gamma$-aminobutyric acid transporter from rat brain. J Biol Chem 267:2563-2568.

Malosio M-L, Marquèze-Pouey B, Kuhse J, Betz H. (1991) Widespread expression of glycine receptor subunit mRNAs in the adult and developing rat brain. EMBO J 10:2401-2409.

May MK, Biscoe TL (1975) An investigation of the foetal rat spinal cord II. Cell Tissue Res 158:251-268.

Nornes HO, Carry M (1978) Neurogenesis in spinal cord of mouse: an audioradiographic analysis. Brain Res 159:1-16.

Nornes HO, Das GD (1974) Temporal pattern of neurogenesis in spinal cord of rat. I. An autoradiographic study-time and sites of origin and migration and settling patterns of ncuroblasts. Brain Res 73:121-138.

Pacholczyck T, Blakely RD, Amara SG (1991) Expression cloning of a cocaine- and antidepressant-sensitive human noradrenaline transporter. Nature 350:350-354.

Püschel AW, Balling R, Gruss P (1990) Position-specific activity of the Hox 1.1-promoter in transgenic mice. Development 108:435-442.

Püschel AW, Gruss P, Westerfield M (1992) Sequence and expression pattern of Pax -6 are highly conserved between zebrafish and mouse. Development 6:591-598.

Puischel AW, O'Connor V, Betz H (1994) The $N$-ethylmaleimide-sensitive fusion protein (NSF) is preferentially expressed in the nervous system. FEBS I ett 347:55-58.

Sambrook J, Fritsch EF, Maniatis T (1989) Molecular cloning: a laboratory manual, $2 \mathrm{~d}$ ed. Cold Spring Harbor, NY: Cold Spring Harbor Laboratory.

Sato K, Kiyama H, Tohyama M (1992) Regional distribution of cells expressing glycine receptor $\alpha 2$ subunit mRNA in the rat brain. Brain Res 590:95-108.

Sato K, Kiyama H, Tohyama M (1993) The differential expression patterns of messenger RNAs encoding non- $N$-methyl-D-aspartate glutamate receptor subunits (GluR1-4) in the rat brain. Neuroscience 52: 515-539.

Schloss P, Mayser W, Betz H (1992) Neurotransmitter transporters: a novel family of integral plasma membrane proteins. FEBS Lett 300: $1-5$.

Schloss P, Püschel AW, Betz H (1994) Neurotransmitter transporters: new members of known families. Curr Opin Cell Biol, in press.

Shimada S, Kitayama S, Lin C-L, Patel A, Nanthakumar E, Gregor P, Kuhar M, Uhl G (1991) Cloning and expression of a cocaine-sensitive dopamine transporter complementary DNA. Science 254:567-578.

Smale ST, Baltimore D (1989) The 'initiator' as a transcription control element. Cell 57:103-113.

Smith KE, Borden LA, Hartig PR, Branchek T, Weinshank RL (1992) Cloning and expression of a glycine transporter reveal colocalization with NMDA receptors. Neuron 8:927-935.

Usdin TB, Mezey E, Chen C, Brownstein, MJ, Hoffman BJ (1991) Cloning of the cocaine-sensitive bovine dopamine transporter. Proc Natl Acad Sci USA 88:11168-11171.

Vaughn JE, Grieshaber JA (1973) A morphological investigation of an early reflex pathways in developing rat spinal cord. J Comp Neurol 148:177-210.

Wang D, Villasante A, Lewis SA, Cowan NJ (1986) The mammalian beta-tubulin repertoire: hematopoetic expression of a novel, heterologous beta-tubulin isotype. J Cell Biol 103:1903-1910. 